\title{
ESTADO NUTRICIONAL E COMPONENTES DA PRODUÇÃO DE PLANTAS DE PIMENTÃO CONDUZIDAS EM SISTEMA DE FERTIRRIGAÇÃO DURANTE INDUÇÃO DE ESTRESSE SALINO EM CULTIVO PROTEGIDO ( ${ }^{1}$ )
}

\author{
MARCELO LEONARDO $\left({ }^{2}\right)$; FERNANDO BROETTO $\left(2^{*}\right)$; ROBERTO LYRA VILLAS BOAS $\left({ }^{3}\right)$; \\ JOSÉ ABRAMO MARCHESE $\left({ }^{4}\right)$; FÁBIO BECHELLI TONIN $\left({ }^{2}\right)$; MAGALI REGINA $\left({ }^{2}\right)$
}

\begin{abstract}
RESUMO
O uso das técnicas de fertirrigação em ambiente protegido vem aumentando no Brasil devido à praticidade de condução e redução dos custos de produção. Apesar dessas vantagens, salienta-se que esta prática também pode trazer riscos, principalmente pelo acúmulo de sais na superfície do solo e na região periférica do bulbo radicular. Em caso de salinização do solo pelo manejo incorreto do sistema podem ocorrer alterações na disponibilidade de nutrientes, com conseqüências fisiológicas no desenvolvimento das plantas. Neste trabalho, utilizou-se o pimentão (Capsicum annuum L.) como planta-modelo para estudos da interferência da salinidade na nutrição das plantas, pela alteração da condutividade elétrica (CE) na solução do solo. Os resultados revelaram indícios de antagonismo entre nutrientes, notadamente entre as formas catiônicas em razão do aumento da concentração de $\mathrm{KCl}$ nos tratamentos com alta CE. A suplementação do solo com adubo orgânico não atenuou os efeitos do aumento da concentração salina e os valores extremos de CE interferiram drasticamente na produção.
\end{abstract}

Palavras-chave: Capsicum annuum L., estresse salino, fertirrigação, nutrição de plantas.

\section{ABSTRACT \\ NUTRITIONAL CONDITION AND YIELD COMPONENTS OF BELL PEPPER PLANTS CONDUCED IN FERTIGATION SYSTEM DURING INDUCTION OF SALINE STRESS IN PROTECTED CULTIVATION}

The use of fertigation techniques in greenhouse is increasing in Brazil due to the facilities and reduction of the costs of production. In spite of these advantages, it is pointed out that this practice can also bring risks, mainly for the accumulation of salts in the surface of the soil and in the peripheric root site of the bulb. In case of soil salinization due to incorrect handling of the system, it can happen alterations in the disponibility of nutrients, with physiological consequences to the development of the plants. In this research, the bell pepper (Capsicum annuum L.) was used as model for studies of the interference of the salinity in plant nutrition and yield. The obtained results revealed some antagonism among nutrients, especially among the cationic forms due to the increase of the $\mathrm{KCl}$ concentration in the treatments with high EC. The supplying of the soil with organic matter did not attenuate the effects of the increase of the saline concentration and the extreme values of EC interfered drastically in the production.

Key words: Capsicum annuum L., salt stress, fertigation, plant nutrition.

$\left({ }^{1}\right)$ Recebido para publicação em 11 de fevereiro de 2005 e aceito em 23 de junho de 2008.

$\left({ }^{2}\right)$ Departamento de Química e Bioquímica - IB/FCA/UNESP, Câmpus de Botucatu, 18618-000 Botucatu (SP). Bolsista do CNPq. E-mail: broetto@ibb.unesp.br $\left(^{*}\right)$ Autor correspondente.

$\left({ }^{3}\right)$ Departamento de Recursos Naturais - FCA/UNESP, Campus de Botucatu, Caixa Postal 510, 18603-970 Botucatu (SP).

$\left({ }^{4}\right)$ Curso de Agronomia, Universidade Tecnológica Federal do Paraná, Campus Pato Branco, 85503-390 Pato Branco (PR). 


\section{INTRODUÇÃO}

O pimentão (Capsicum annuum L.) vem se destacando como uma das oleráceas mais consumidas no Brasil, com aumento da produção nos últimos anos, principalmente em ambiente protegido, comparado a outras culturas (Melo, 1997).

O cultivo protegido e a fertirrigação, quando bem dimensionados, são ferramentas efetivas para o aumento da produtividade em espécies oleráceas. Além disso, esta forma de cultivo garante proteção contra intempéries, além de reduzir o ataque de pragas e o consumo de água de irrigação por unidade produzida. Comparada ao cultivo convencional, a fertirrigação pode favorecer uma economia de cerca de $50 \%$ no consumo de água durante o ciclo das culturas (StANGHeLlini, 1993). No entanto, SiLva et al. (1999) argumentam que existe a possibilidade de aumento do potencial salino do solo, sendo a aplicação excessiva de fertilizantes e o manejo do solo e da irrigação fatores que devem ser bem dimensionados, a fim de evitar o processo de salinização.

Em virtude da condição de salinização do solo, podem ocorrer desordens nutricionais, induzindo relações antagônicas entre nutrientes na planta, o que reduz significativamente os rendimentos das culturas (Grattans e Grieve, 1993). Santos e Muraoka (1997) discutem que as propriedades químicas e físicas dos solos salinizados restringem a disponibilidade de nutrientes para as plantas. Para sua absorção, os nutrientes tornam-se disponíveis para as plantas quando estão na forma solúvel e com balanço iônico adequado na solução do solo (MARFÁ, 1987).

A matéria orgânica, em razão de suas características de carga elétrica, pode alterar a condutividade elétrica (CE) do solo, atenuando os efeitos da salinidade às plantas, o que pode favorecer o ambiente radicular e diminuir os efeitos deletérios da salinidade. Assim, conforme Araújo (1992), esses materiais de origem animal ou vegetal deveriam ser utilizados freqüentemente nos solos salinizados.

Cruciani (1987) destaca que sob condições de estresse salino, a coloração das folhas de pimentão (Capsicum annuиm L.) pode se tornar verde-azuladaescura, com maior espessura e cerosidade; nas raízes pode haver diminuição do alongamento e suberização, o que afeta a absorção de água e nutrientes, com a conseqüente redução da produtividade.

A salinização do solo pode influenciar na redução na disponibilidade de água para as plantas em vista da redução do potencial total ocasionado pela contribuição do potencial osmótico (LiMA,1997).
Este trabalho objetivou estudar os efeitos da condutividade elétrica, ocasionados pelo excesso de sais no estado nutricional e nos componentes da produção de plantas de pimentão. Além disso, verificar possível atenuação dos efeitos da salinidade, em virtude da aplicação de adubo orgânico.

\section{MATERIAL E MÉTODOS}

O experimento foi desenvolvido em estrutura de proteção tipo arco, de 7,0 x 12,5 m e pé direito de $3,0 \mathrm{~m}$. Foi adotado o delineamento inteiramente casualizado, em esquema fatorial $4 \times 2$, com quatro repetições, sendo quatro níveis de CE com presença e ausência de adubo orgânico na cultura de pimentão, conforme o Tabela 1.

Tabela 1. Níveis de CE do solo, com presença ou ausência de adubo orgânico

\begin{tabular}{|c|c|c|c|c|}
\hline $\begin{array}{l}\text { Adubo } \\
\text { orgânico }\end{array}$ & Níve & is de CE ( & (S $\left.\mathrm{m}^{-1}\right)$ & \\
\hline Presença & $1,5 \mathrm{dS} \mathrm{m}^{-1}$ (controle) & $3,0 \mathrm{dS} \mathrm{m}^{-1}$ & $4,5 \mathrm{dS} \mathrm{m}^{-1}$ & $6,0 \mathrm{dS} \mathrm{m}^{-1}$ \\
\hline Ausência & $1,5 \mathrm{dS} \mathrm{m}^{-1}$ (controle) & $3,0 \mathrm{dS} \mathrm{m}^{-1}$ & $4,5 \mathrm{dS} \mathrm{m}^{-1}$ & $6,0 \mathrm{dS} \mathrm{m}^{-1}$ \\
\hline
\end{tabular}

Foram utilizadas caixas de amianto $(36 \times 36 \times$ $30 \mathrm{~cm} ; 30 \mathrm{~L}$ ) previamente impermeabilizadas com tinta betuminosa. As caixas foram preenchidas com Latossolo Vermelho-Escuro distrófico textura média $\left(\mathrm{Le}_{\mathrm{d}}\right)$ feita por (CARvalho et al, 1983), coletado na Fazenda Experimental Lageado - FCA, Câmpus da UNESP, em Botucatu (SP), na gleba denominada Patrulha.

Nas caixas com capacidade de $30 \mathrm{~L}$, do tratamento-controle, aplicou-se $0,24 \mathrm{~g} \mathrm{planta}^{-1}$ de $\mathrm{N}$ na forma de nitrato de cálcio $\mathrm{Ca}\left(\mathrm{NO}_{3}\right)_{2}$ e $0,2 \mathrm{~g}_{\text {planta }}$ ${ }^{1}$ de $\mathrm{K}$ na forma de $\mathrm{KCl}$, de forma parcelada a cada três dias, mantendo-se a $\mathrm{CE}$ do solo em torno de 1,5 $\mathrm{dS} \mathrm{m}^{-1}$, considerado limiar para a cultura do pimentão, segundo LORENS e MAYNARD (1988). Com base nas equações de salinização do solo sob efeito dos dois tipos de adubos $\left(\mathrm{CE}=0,053 \mathrm{~g} \mathrm{Ca}\left(\mathrm{NO}_{3}\right)_{2}+0,4029\right.$ e CE $=0,0967 \mathrm{~g} \mathrm{KCl}+0,38)$ foram aplicadas quantidades de nitrato de cálcio $\mathrm{Ca}\left(\mathrm{NO}_{3}\right)_{2}$ e cloreto de potássio $\mathrm{KCl}$ visando elevar a CE para 3,0; 4,5 e 6,0 dS mAvaliou-se a cada três dias o nível da CE do solo e, de acordo com a curva de salinização, ajustaram-se os níveis de CE para cada tratamento, a fim de manter os valores preestabelecidos (Tabela 2).

$\mathrm{O}$ nitrato de cálcio $\mathrm{Ca}\left(\mathrm{NO}_{3}\right)_{2}$ e o cloreto de potássio $\mathrm{KCl}$ foram aplicados pelo sistema de gotejamento, sendo que os gotejadores foram instalados a $15 \mathrm{~cm}$ do colo da planta, sobre a superfície do solo, com vazão de $2 \mathrm{~L} \mathrm{~h}^{-1}$. O calcário, o adubo orgânico e o fósforo foram incorporados ao solo durante o preenchimento das caixas. 
Tabela 2. Quantidades totais de $\mathrm{Ca}\left(\mathrm{NO}_{3}\right)_{2}$ e $\mathrm{KC} 1$ utilizados para salinização e manutenção da CE do solo, para cada tratamento

\begin{tabular}{lcc}
\hline Tratamentos $(\mathrm{CE})$ & $\mathrm{Ca}\left(\mathrm{NO}_{3}\right)_{2}$ & $\mathrm{KCl}$ \\
\hline $1,5 \mathrm{dS} \mathrm{m}^{-1}$ & $56 \mathrm{~g}$ & $15 \mathrm{~g}$ \\
$3,0 \mathrm{dS} \mathrm{m}^{-1}$ & $98 \mathrm{~g}$ & $35 \mathrm{~g}$ \\
$4,5 \mathrm{dS} \mathrm{m}^{-1}$ & $153 \mathrm{~g}$ & $55 \mathrm{~g}$ \\
$6,0 \mathrm{dS} \mathrm{m}^{-1}$ & $198 \mathrm{~g}$ & $101 \mathrm{~g}$ \\
\hline
\end{tabular}

Antes do início do cultivo, o solo foi adubado conforme recomendação de VILlas BôAs (2001), para a cultura do pimentão. O calcário dolomítico (PRNT = 91\%) foi aplicado para elevar o valor de $\mathrm{V}$ a $80 \%$, segundo Trani et al. (1996). Para o fósforo, aplicou-se $150 \mathrm{mg} \mathrm{P} \mathrm{L}^{-1}$ de solo, sendo $75 \mathrm{mg}$ de $\mathrm{P}$ como superfosfato simples $\left(18 \% \mathrm{P}_{2} \mathrm{O}_{5}\right)$ e $75 \mathrm{mg}$ na forma de termofosfato Master $+\mathrm{S}\left(17,5 \% \mathrm{P}_{2} \mathrm{O}_{5}\right)$. Nos tratamentos suplementados com adubo orgânico foram misturados ao solo $260 \mathrm{~g} \mathrm{caixa}^{-1}$ de esterco de curral seco, calculando-se a quantidade a ser aplicada em função da área da caixa $(36 \times 36 \mathrm{~cm})$, equivalente a $2 \mathrm{~kg} \mathrm{~m}^{-2}$ do esterco de curral.

Aos 136 dias após o transplantio (DAT), aplicou-se Zn e B via foliar (0,5\% de sulfato de zinco e $0,1 \%$ de Bórax), em virtude do aparecimento de sintomas visuais, como queda de botões florais e diminuição dos internódios da extremidade da planta.

Foram utilizadas mudas do híbrido Elisa (Rogers), com transplante aos 50 dias após a semeadura, quando havia cinco folhas definitivas.

As medidas da CE do solo foram monitoradas através da análise da solução do solo $\mathrm{CE}_{\mathrm{scp}}$ (condutividade elétrica da solução da cápsula porosa), retirada por um extrator de solução, levandose em consideração, no momento da extração da solução do solo, o teor de água de cada caixa $U_{c p}$ (umidade da cápsula porosa). Posteriormente, utilizando-se a equação da curva de retenção de água no solo, os valores da $\mathrm{CE}\left(\mathrm{dS} \mathrm{m}^{-1}\right)$ foram transformados em um valor corrigido ( $\left.\mathrm{CE}_{\text {corrigida }}\right)$, em relação ao teor de água no solo, quando saturado $\left(\mathrm{U}_{\mathrm{s}}\right.$ = umidade de saturação), conforme a expressão: $\mathrm{CE}_{\text {corrigida }}=\left(\mathrm{CE}_{\mathrm{scp}} \cdot \mathrm{U}_{\mathrm{scp}}\right) / \mathrm{U}_{\mathrm{s}}$

Determinou-se o teor de água no solo, com o uso de um tensiômetro eletrônico de punção, com medidas expressas em bar $(-0,01$ a $-1,00$ bar). Para a definição do teor real de água do solo em relação à tensão dada pelo aparelho, efetuou-se uma curva de retenção de água do solo ajustada pela equação logarítmica $(y=-0,1331 \operatorname{Ln} x+0,4716)$; em que: $x=$ tensão expressa em bar.
O extrator de solução do solo e o tensiômetro foram instalados de forma permanente nas caixas de cultivo a uma distância de $15 \mathrm{~cm}$ da planta e à profundidade de $20 \mathrm{~cm}$ do centro da cápsula porosa.

A reposição da água ocorreu sempre que a leitura da tensão de água no solo, atingisse valor superior a - $20 \mathrm{KPa}(-0,20$ bar), mantendo o solo com uma tensão de - $15 \mathrm{KPa}(-0,15$ bar).

As plantas foram conduzidas livremente com duas ou três hastes conforme descrito por VILLAs BôAS (2001). Durante o experimento, realizou-se a desbrota até a altura da primeira flor, o que favoreceu o crescimento da planta. Para prevenção do ataque de pragas, as plantas foram pulverizadas quinzenalmente com inseticidas adequados.

No fim do experimento (155 DAT), foram coletadas e analisadas amostras de folhas, caule e frutos, no laboratório de análise foliar do Departamento de Recursos Naturais - Ciência do Solo, FCA/UNESP, conforme método descrito por Malavolta et al. (1997). Efetuaram-se feitas 15 colheitas durante o ciclo da cultura, determinandose a massa média de frutos e o número de frutos por planta. Os dados obtidos foram analisados por regressão linear para os parâmetros de produção e para a concentração de nutrientes na matéria seca de folhas, frutos e caule.

\section{RESULTADOS E DISCUSSÃO}

Os valores da concentração de $\mathrm{N}$ em folhas de pimentão, analisados para o tratamento- controle (Figura 1), foram semelhantes às médias reportadas por Villas BôAs (2001), de $36 \mathrm{~g} \mathrm{~kg}^{-1}$ e $38 \mathrm{~g} \mathrm{~kg}^{-1}$, em aplicação convencional e fertirrigadas respectivamente. Entretanto, para os tratamentos que induziram maior $\mathrm{CE}$, os valores médios de $\mathrm{N}$ foram superiores a essas médias, mantendo-se em patamar próximo a $40 \mathrm{~g} \mathrm{~kg}^{-1}$. As plantas do controle retiveram menor concentração de $\mathrm{N}$ nas folhas, embora este tenha sido o tratamento mais produtivo. A alta concentração de $\mathrm{N}$ nas folhas em resposta a tratamentos sob maior CE no solo pode ser justificada pelo acúmulo de nitrato nos vacúolos, de acordo com Martinez e Cerda (1989). Segundo esses autores, o acúmulo de nitrato nas folhas pode influenciar o balanço cátion - ânion e o equilíbrio osmótico. Outra hipótese a ser considerada, seria a biossíntese de compostos nitrogenados que funcionariam como fontes potenciais de $\mathrm{N}$, que devido a sua natureza metabólica constitutiva, preservariam o elemento, desviando seu uso da síntese de proteínas, conforme discutido por PesSARAKLI et al. (1989). 

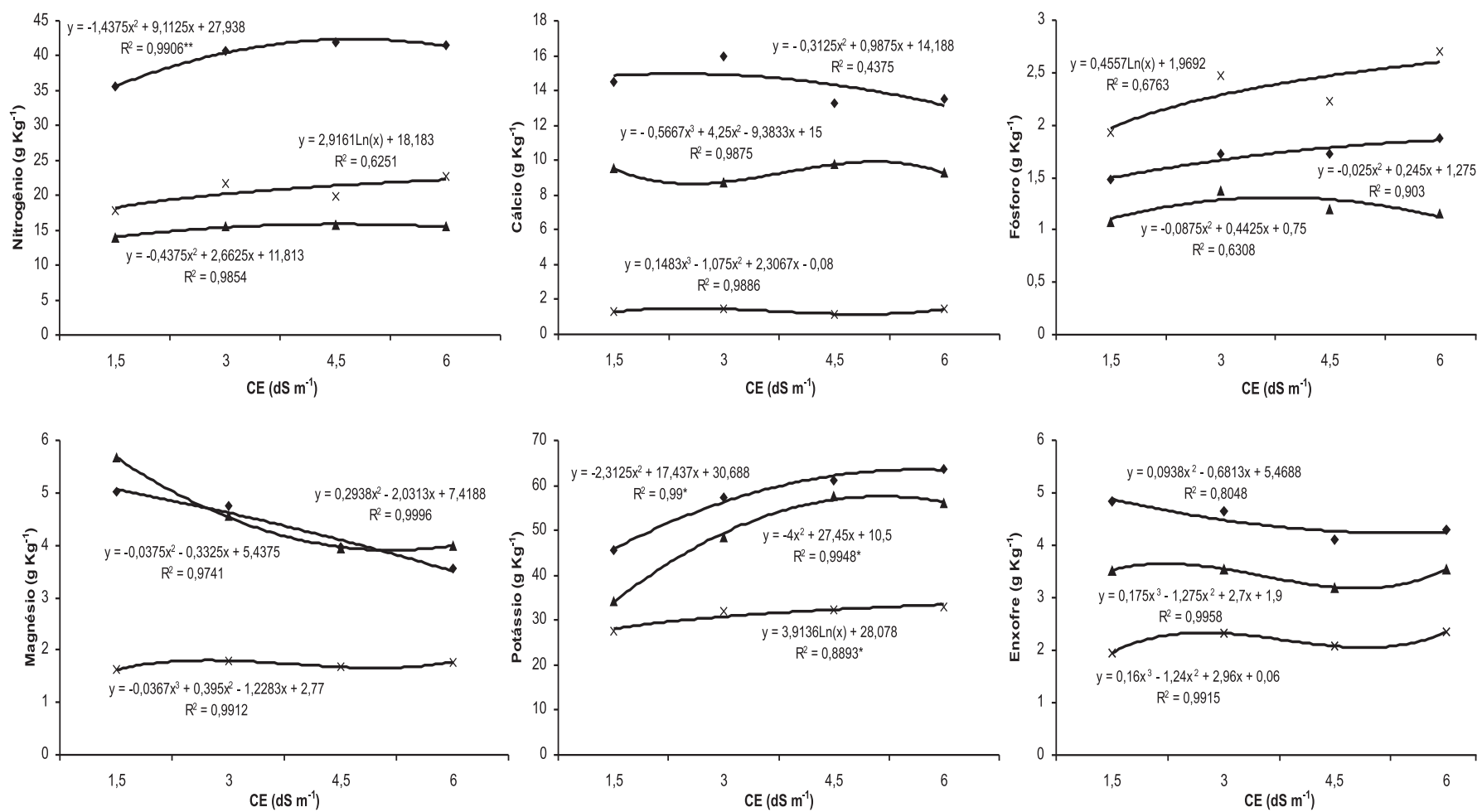

Figura 1. Concentração de $\mathrm{N}, \mathrm{P}, \mathrm{K}, \mathrm{Ca}, \mathrm{Mg}$ e $\mathrm{S}$ na matéria seca (MS) de diferentes tecidos de pimentão 'Elisa', aos 155 DAT, em função de diferentes níveis de CE da solução do solo e suplementação com adubo orgânico, em que: $\bullet$, Folha; x, Fruto; $\mathbf{\Delta}$, Caule.

As concentrações de $\mathrm{N}$ retidas no caule e nos frutos (Figura 1) foram inferiores às observadas nas folhas e semelhantes às constatadas por VILLAS BôAS (2001), posto que no tratamento com CE de $6,0 \mathrm{dS} \mathrm{m}^{-}$ ${ }^{1}$ nos frutos havia concentração média de $\mathrm{N}$ igual a $23 \mathrm{~g} \mathrm{~kg}^{-}$, porém não se observou efeito de CE.

A concentração de $P$ nas folhas atingiu valores abaixo do recomendado por TRANI et al. (1996) para esta cultura. A baixa concentração de P nas folhas pode ser explicada pela fonte de cálcio utilizada na adubação (nitrato de cálcio) ou, ainda, possivelmente, pela rápida formação de zonas de depleção. Reforçando esta hipótese, JoNES Jr. et al. (1991) observam que o Ca pode induzir a precipitação de quantidades consideráveis de $\mathrm{P}$, principalmente em solos mais arenosos. Segundo VILlas BôAS (2001), pode ocorrer diminuição da concentração de $\mathrm{P}$, pelo uso de $\mathrm{Ca}\left(\mathrm{NO}_{3}\right)_{2}$, em especial quando aplicados via fertirrigação localizada.

As concentrações de $\mathrm{P}$ nas folhas foram inferiores às constatadas por VILLAS BOAS (2001), em média $3,0 \mathrm{~g} \mathrm{~kg}^{-1}$. Neste experimento, sugere-se que a menor disponibilidade de $\mathrm{P}$, pode ter sido a provável causa do menor crescimento das plantas (LEONARDO, 2003), considerando-se que este elemento é importante nas etapas de síntese de proteínas, carboidratos e lipídeos. As concentrações de P no caule foram inferiores aos valores contatados por MiLLER et al. (1979).
De acordo com a figura 1, nota-se que as concentrações de $\mathrm{K}$ nos frutos aumentaram diretamente com o acréscimo da CE do solo, em conseqüência da utilização de $\mathrm{KCl}$ nesses tratamentos para a manutenção da CE. Em folhas e no caule, verificou-se um ponto máximo para a concentração de potássio.

HAGin e TUCKER (1982) demonstraram que a elevação do teor de $\mathrm{K}$ no solo pode induzir desequilíbrio nutricional para as plantas. No presente experimento, a alta concentração de $\mathrm{K}$ na solução do solo pode ter propiciado a diminuição da absorção de outros cátions como Ca e Mg.

O potássio é um dos elementos relacionados ao controle osmótico da célula. Segundo GREENWAY e MUNNS (1980), a absorção intracelular de íons é um componente importante do ajustamento osmótico necessário para a adaptação a condições de salinidade. O estresse primário envolve danos fisiológicos em nível de membrana, como alterações na permeabilidade e efluxo de íons (Levitt, 1980). Nessa situação, a concentração de $\mathrm{K}$ exerce papel importante como componente do sistema de troca de iônica.

A concentração de Ca nas folhas de pimentão diminuiu, ocasionado pelo aumento da $\mathrm{CE}$, provavelmente induzido pelo antagonismo com o K. Comparando-se os tratamentos com e sem adubo orgânico, verificou-se que não houve efeito da CE nos 
teores dos nutrientes, exceto para potássio e cálcio nas folhas e magnésio nos frutos (Figura 1). A justificativa para esta interação é que o adubo orgânico, em virtude de suas características físicoquímicas pode ter atenuado os efeitos da CE, conforme cita ARAúJo (1992). Esse autor verificou que, em solo salinizado, em parcelas tratadas com adubo orgânico e drenagem, a CE proporcionou níveis tolerados para a maioria das culturas de importância econômica.
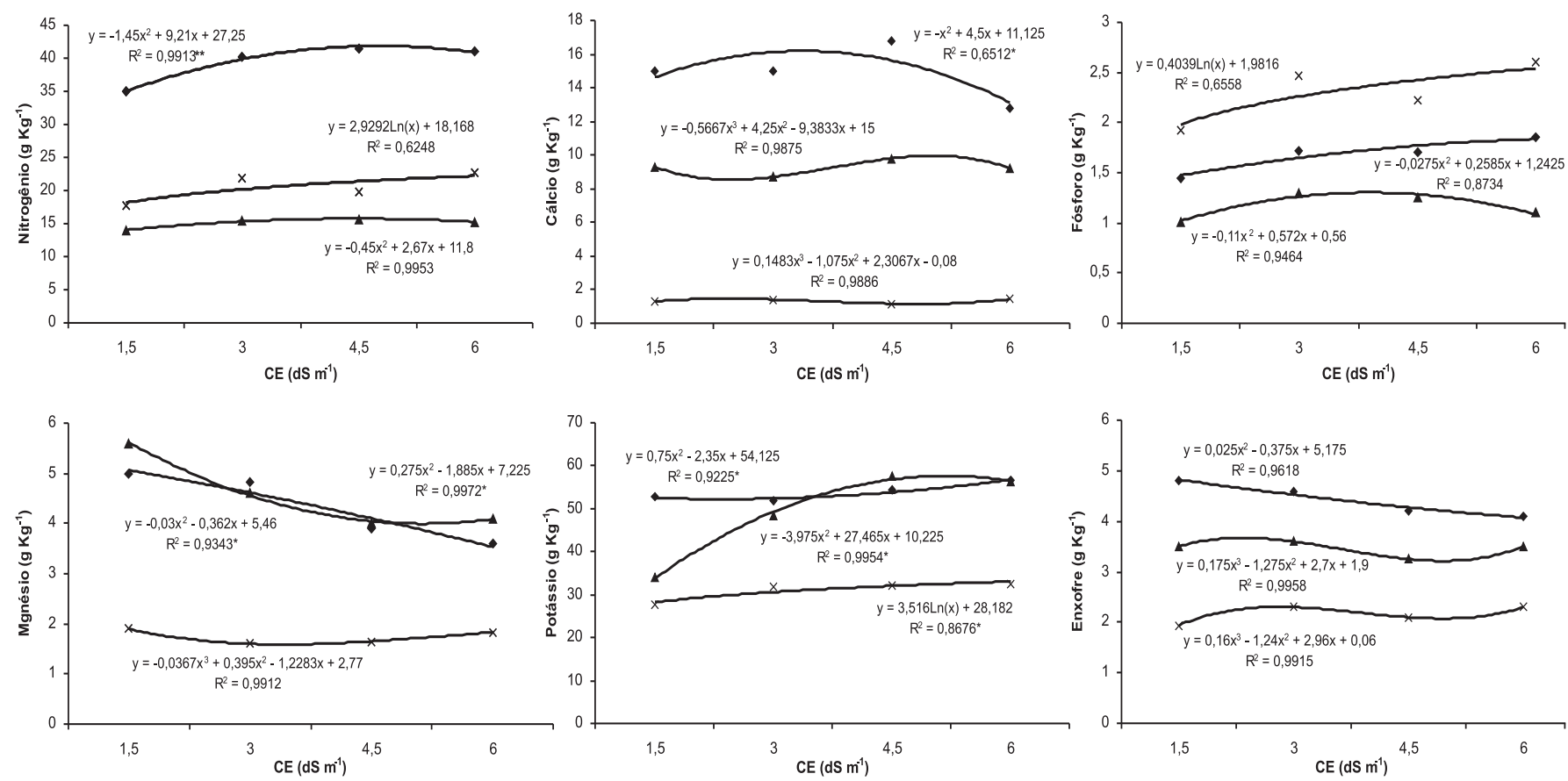

Figura 2. Concentração de $\mathrm{N}, \mathrm{P}, \mathrm{K}, \mathrm{Ca}, \mathrm{Mg}$ e $\mathrm{S}$ na matéria seca (MS) de diferentes tecidos de pimentão 'Elisa', aos 155 DAT, em função de diferentes níveis de CE da solução do solo e na ausência de adubo orgânico, em que: $\bullet$, Folha; x, Fruto; $\mathbf{\Delta}$, Caule.

As baixas concentrações de Ca induzidas nos tratamentos com maior $\mathrm{CE}$, refletiram em efeitos visuais, como o aparecimento de folhas retorcidas, deformidades nos frutos e podridão apical. Crescendo em condições consideradas padrão, nas plantas do tratamento-controle não ocorreu qualquer sintoma visual de deficiência de cálcio.

Em condições salinas, com alta CE do solo, pode ocorrer redução na disponibilidade de água, em função de ajustamento osmótico. Considerando-se que o Ca é transportado via xilema, a indisponibilidade de água pode interferir na sua translocação. Portanto, durante o crescimento do fruto, devem ter ocorrido oscilações no potencial de água na planta e, conseqüentemente, no fornecimento de $\mathrm{Ca}$, principalmente nos tratamentos com maior CE.

Para as concentrações de $\mathrm{Mg}$ no caule e nas folhas, verificou-se que em função do aumento da CE, houve diminuição da concentração de $\mathrm{Mg}$ em efeito antagônico ao K, semelhante ao observado para o elemento Ca. Os efeitos antagônicos entre cátions relativos à salinidade promovida pelo $\mathrm{KCl}$ foram mais pronunciados em relação ao $\mathrm{Mg}$, comparado aos efeitos sobre o Ca.
Para as concentrações de $S$ em folhas, caule e frutos, observa-se que os teores de $S$ no caule foram levemente incrementados com o aumento da CE, diferentemente do observado para as folhas. Considerando-se que nos tratamentos com maior CE a quantidade de $\mathrm{N}$ aplicada foi maior, os resultados concordam com os de Villas BôAs (2001) que demonstrou haver uma correlação entre os dois elementos, pelo menos nos tecidos do caule.

Efeitos sobre a estrutura do solo são geralmente associados à aplicação de adubo orgânico (JANICK, 1966) e como fonte de nutrientes para o aumento da fertilidade (PRIMAVESI, 1980). Neste ensaio, a pouca influência da aplicação de adubo orgânico como atenuante dos efeitos da salinização mantevese como incógnita. A baixa quantidade aplicada $(2,0$

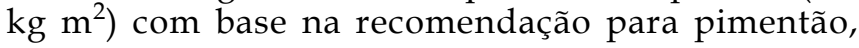
pode ter sido o fator limitante.

Em relação à produção, verificou-se que existe relação inversa entre a $\mathrm{CE}$ do solo e a massa média dos frutos. Assim, quanto maior a CE do solo, menor a massa média dos frutos (Figura 3). Pela equação define-se que para cada incremento de $1,0 \mathrm{dS} \mathrm{m}^{-1}$ na CE do solo ocorre, em média, um decréscimo de $15 \%$ na massa média do fruto. 
Mesmo para o tratamento-controle, os valores de massa média dos frutos foram relativamente pequenos, comparados aos de outros trabalhos da literatura para esta cultura, provavelmente em conseqüência da temperatura elevada (superiores a 35 $\left.{ }^{\circ} \mathrm{C}\right)$ no período experimental. $\mathrm{O}$ alto valor de $\mathrm{CE}$ do solo interferiu na capacidade da planta em relação aos índices de pegamento de frutos, corroborando resultados anteriores (VILlas-BôAS, 2001; LeONARDO, 2003). Este dano fisiológico é freqüentemente relacionado ao baixo teor de Ca à disposição dos tecidos nessa situação de estresse ou à interação negativa entre $\mathrm{Ke} \mathrm{Ca}$.

Os tratamentos com CE mais elevada induziram as plantas a uma redução de $55 \%$ do total de frutos produzidos (Figura 3 ) em relação ao tratamento controle $\left(1,5 \mathrm{dS} \mathrm{m}^{-1}\right)$.
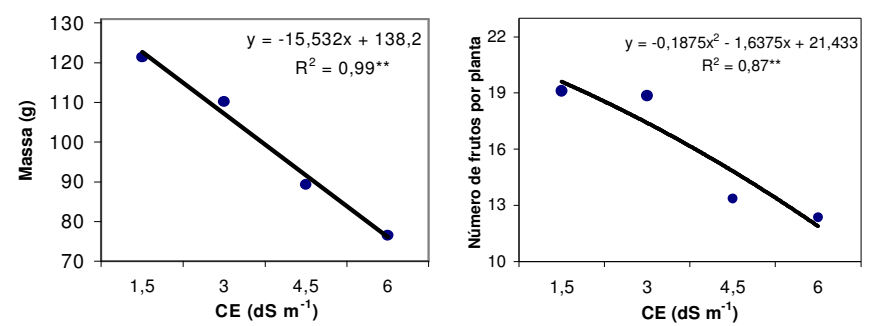

Figura 3. Massa média de frutos e número de frutos por planta em função de diferentes níveis de CE do solo.

\section{CONCLUSÕES}

1. Várias formas catiônicas comportaram-se de forma antagônica em vista do aumento da CE no solo. Este antagonismo contribuiu para alteração da composição mineral de diferentes órgãos e frutos estudados, com efeitos negativos sobre a fisiologia e produção das plantas.

2. A aplicação de matéria orgânica pouco influenciou na atenuação dos efeitos da salinização do solo.

\section{REFERÊNCIAS}

ARAÚJO, R.C. Uso do gesso agrícola e matéria orgânica no manejo de um solo salinizado. 1992. 54 f. Dissertação (Mestrado em Agronomia/ Manejo e Conservação de Solos)Universidade Federal da Paraíba, Areia, PB.

CARVALHO, W.A.; ESPÍNDOLA, C.R.; PACOLLA, A.A. Levantamento de Solos da Fazenda Lageado-Estação Experimental "Presidente Médici". Botucatu: UNESP/FCA, 1983. 95p.

CRUCIANI, D. E. A drenagem na agricultura. 4. ed, São Paulo: Nobel, 1987, 337p.
GRATTANS, S.R.; GRIEVE, C.M. Mineral nutrient acquisition and response by plants grown in saline environments. In: PESSARAKLI, M. (Ed). Plant and Crop Stress. Tucson: Marcel Dekker, 1993. p.203-226.

GREENWAY, H.; MUNNS, R. Mechanisms of salt tolerance in non-halophytes. Annual Review of Plant Physiology, Palo Alto, v.31: p. 149-190, 1980.

HAGIN, J.; TUCKER, B. Fertilization of dryland and irrigated soils. Advanced Series in Agricultural Sciences, Berlin: Springer-Verlag, 1982. v.12, p.188-198.

JANICK, J.; Orientação do crescimento da planta In: A ciência da horticultura. Rio de Janeiro: Freitas Bastos, 1966. cap.7, p.203-37.

JONES JR, J. B.; WOLF, B., MILLS, H. A. Plant Analysis Handbook. Athens: Micro-Macro Publishing, 1991. 213 p.

LEONARDO, M. Estresse salino induzido em plantas de pimentão (Capsicum annuum L.) fertirrigadas e seus efeitos sobre a produtividade e parâmetros bioquímicos. 2003. 100 f. Dissertação (Mestrado em Agronomia/Irrigação e Drenagem) Faculdade de Ciências Agronômicas Universidade Estadual Paulista, Botucatu, SP.

LEVITT, J. Responses of plants to environmental stresses. In: WATER radiation salt and other stresses. New York: Academic Press, 1980. v. 2. p. 25-211.

LIMA, L.A. Efeitos de sais no solo e na planta. In: GHEYI; H. R.; QUEIROZ, J. E.; MEDEIROS, J. M. (Ed.). SIMPÓSIO MANEJO E CONTROLE DA SALINIDADE NA AGRICULTURA. Campina Grande: UFPB-SBEA, 1997. p.113-136.

LORENS, O.A.; MAYNARD, D.N. Knott's handbook for vegetables growers. 3.ed., New York: John Wiley and Sons, 1988. 456p.

MALAVOLTA, E.; VITTI, G.C.; OLIVEIRA, S.A. Avaliação do estado nutricional de plantas: princípios e aplicações. Piracicaba: Potafos, 1997. 304 p.

MARFÁ, O. Fertirriego. Revista Sociedad Española de Horticultura, Madrid, v.68, p.32-33, 1987.

MARTINEZ, V.; CERDA, A. Nitrate reductase activity in tomato and cucumber leaves as influenced by $\mathrm{NaCl}$ and $\mathrm{N}$ source. Journal of Plant Nutrition, New York, v.12, p.1335 $1350,1989$.

MELO, A.M.T. Análise genética de caracteres de fruto em híbridos de pimentão. 1997. 112 f. Tese (Doutorado em Agronomia/Genética e Melhoramento de Plantas) - Escola Superior de Agricultura "Luiz de Queiróz" - USP Piracicaba, SP.

MILLER, C.R.; MICCOLLUM, R.E.; CLAIMON, N.S.; Relationship between growth of bell pepper and nutrient accumulation during ontogenynin field environments. Journal of American Society for Horticultural Sciences, New York, v.104, n.6, p.852-857, 1979. 
PESSARAKLI, M.; HUBER, J.T.; TUCKER, T.C. Protein synthesis in green beans under salt stress with two nitrogen sources. Journal of Plant Nutrition, New York, v. 12, n. 11, p. 1361-1377, 1989.

PRIMAVESI, A.M. O manejo ecológico do solo. São Paulo: Nobel, 1980. 541p.

SANTOS, R.V.; MURAOKA, T. Interações salinidade e fertilidade do solo. In: GHEYI, H.R.; QUEIROZ, J.E.; MEDEIROS, J.M. (Ed). Manejo e controle da salinidade na agricultura. Campina Grande: UFPB, SBEA. 1997. p. 289-315.

STANGHELLINI, C. Evapotranspiration in greenhouse with special reference on Mediterranean conditions. Acta Horticulturae, The Hague, v. 335, p. 296-304, 1993.

SILVA, E.F.F., DUARTE, S.N., COELHO, R.D. Salinização dos solos cultivados som ambientes protegidos no estado de São Paulo. Fertirrigação. Guaíba: Ed. Agropecuária, 1999. p. 267-278.

TRANI, P.E.; MELO, A.M.T.; PASSOS, F.A.; TAVARES, M.; NAGAI, H. \& SCIVITTARO, W.B. Berinjela, jiló, pimentahortícola e pimentão. In: RAIJ, B. van; CANTARELLA, H.; QUAGGIO, J.A.; FURLANI, A.M.C. (Ed). Recomendação de adubação e calagem para o estado de São Paulo. 2.ed. Campinas, IAC / Fundação IAC, 1996. p.150-151.

VILLAS BOAS, R. L. Doses de nitrogênio para o pimentão aplicadas de forma convencional e através da fertirrigação. 2001. 123 f. Tese (Livre Docência) - Faculdade de Ciências Agronômicas, Universidade Estadual Paulista, Botucatu, SP. 